\title{
An innovation ecosystem for for-profit medical services at a university medical centre: research and sustainable development
}

\author{
Varvara Altunina, Liubov Shcherbinina, and Natalia Lukyanova \\ Immanuel Kant Baltic Federal University, 14 Aleksandra Nevskogo St, 236041 Kaliningrad, Russia
}

\begin{abstract}
This article presents the results of research and development of an innovation ecosystem for for-profit medical services provided to residents of the Kaliningrad region at the medical centre of the Immanuel Kant Baltic Federal University. These services contribute to the sustainable development of regional healthcare in line with the current green growth trends. A universal model of an ecosystem for providing medical services to residents of a region is proposed, along with a model for a platform ecosystem of a university medical centre. The desk and field marketing research enabled the first stage of ecosystem creation - the formation of the value proposition, which is the provision of "complex case" medical services. This approach to medical care will preserve regional human resources and encourage residents to pay more attention to their health, the environment, and natural resources. Another positive result will be harmonising the environmental needs of society with global trends in sustainability and green growth.
\end{abstract}

\section{Introduction}

The sustainable development of regional economic sectors in line with the global trends of green growth contributes to the sustainable development of the territory. As to regional healthcare, its main indicators are the health condition, living standards, and well-being of regional residents. Therefore, green growth in medical care is impossible without the population's commitment to healthy lifestyles or the emergence of eco-consciousness and environmental needs. The 2030 UN Agenda for Sustainable Development, which was adopted in 2015, particularly its third goal "Good health and well-being" [1], names sustainable development of regional healthcare a pressing challenge. Responding to it requires joint efforts from public authorities, the business community, and other stakeholders, and their success will depend on many factors: integration processes, the introduction of advanced medical technologies and practices, the format of the health services, recruitment of specialists from outside the region and country, etc.

Many current processes call for new approaches to organising and doing business. Among them are the growing hyperconnectedness of business entities, the increasing speed of information, goods, and services exchange, Internet-powered upscaling of enterprises, a change in the model of consumer behaviour accompanied by a rise in client involvement in 
product/service creation, and the need for continuous communication between customers and the company.

Today, the most sustainable economic actors are not companies but ecosystems that are built on close cooperation between stakeholders on the supply side and the demand side. Among them are customers, partner companies, suppliers, investors, business incubators, etc. This cooperation generates a synergy effect and has several far-reaching consequences:

- the final customer value is created by the company in collaboration with its partners, consumers, and other participants, with each actor benefitting from the process;

- the organisation and control of interactions between all participants in the business processes are becoming more important than owning material resources;

- competition and cooperation become the main elements in the system of organisational relations between ecosystem units [2, p.90];

- data on customers and partners become a valuable resource.

Business ecosystems (not to be confused with biological ecosystems) first appeared in the literature at the turn of the century (Moore (1993, 1997) [3-4]). Russian and international economists have developed the concept into an ecosystem theory. For example, Kleyner (2018) [2] and Jacobides, Cennamo, and Gawer (2018) [5] have made a noteworthy contribution. The theoretical findings have been put into business practice, particularly in the financial and credit sector [6].

This study defines a regional ecosystem for for-profit medical services as a socioeconomic entity consisting of a collaboration of independent economic, social, organisational actors ( These are medical, health improvement, educational, and finance and credit institutions; telecommunication companies; regional offices of tax, pension, and social security services; regional ministry of health, and other local actors.) and the results of their efforts, an entity capable of independent functioning and long-term development based on the circulation of material, information, labour, and other resources (see [2, p. 89]). Fig. 1 shows a universal model of a regional ecosystem.

Creating, investigating, and improving a modern ecosystem for for-profit medical services is a complex process that requires:

- a business model based on an information platform;

- a system for market interactions (goods-money-goods) and non-market communications (exchange of knowledge, connections, information, competencies, etc.) between ecosystem participants;

- a clearly understood value reflecting the relationship between the price, properties, and quality of the service;

- $\quad$ an entirely new attitude of regional residents to their health, the environment, natural resources, etc.

In Russia and abroad, platform business ecosystems have developed to varying degrees in different fields, ranging from advanced and well-researched ecosystems of the banking sector to less visible ecosystems of for-profit medical services. 


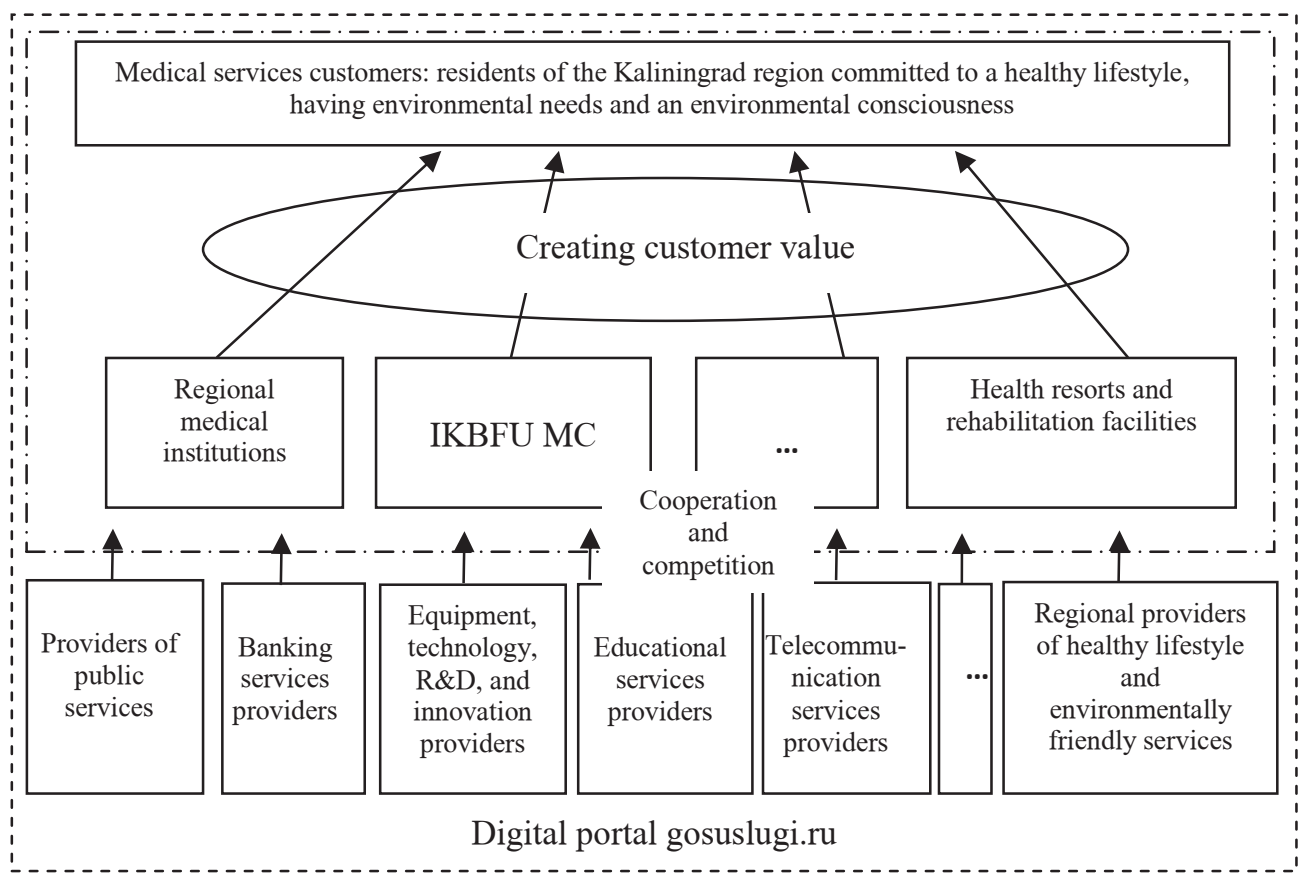

Fig. 1. A regional ecosystem for providing medical services to residents (prepared by the authors based on $[5, \mathrm{p} .2261])$

The above considerations and the specific features of the study object necessitate a narrow definition of a platform ecosystem for for-profit medical services at the medical centre of the Immanuel Kant Baltic Federal University (IKBFU MC). According to the narrow definition, this ecosystem is a structure based on an information platform and consisting of interacting entities, their cooperation mechanisms, and their environment; it is a structure seeking to create a key value proposition by supporting direct contacts and transaction between all participants in the system (see [7, p. 39]). We fully agree with James F. Moore's opinion that "in a business ecosystem, companies 'co-evolve' capabilities around a new innovation: they work cooperatively and competitively to support new products, satisfy customer needs, and eventually incorporate the next round of innovations" [2, p. 76].

The agents of the ecosystem for for-profit medical services provided at the IKBFU MC are the MC, the Fabrika science park, the Institute of Medicine, the Institute of Economics, Management, and Tourism, the Institute of Physics, and Mathematics, partner medical organisations, reference groups, customers, etc. 


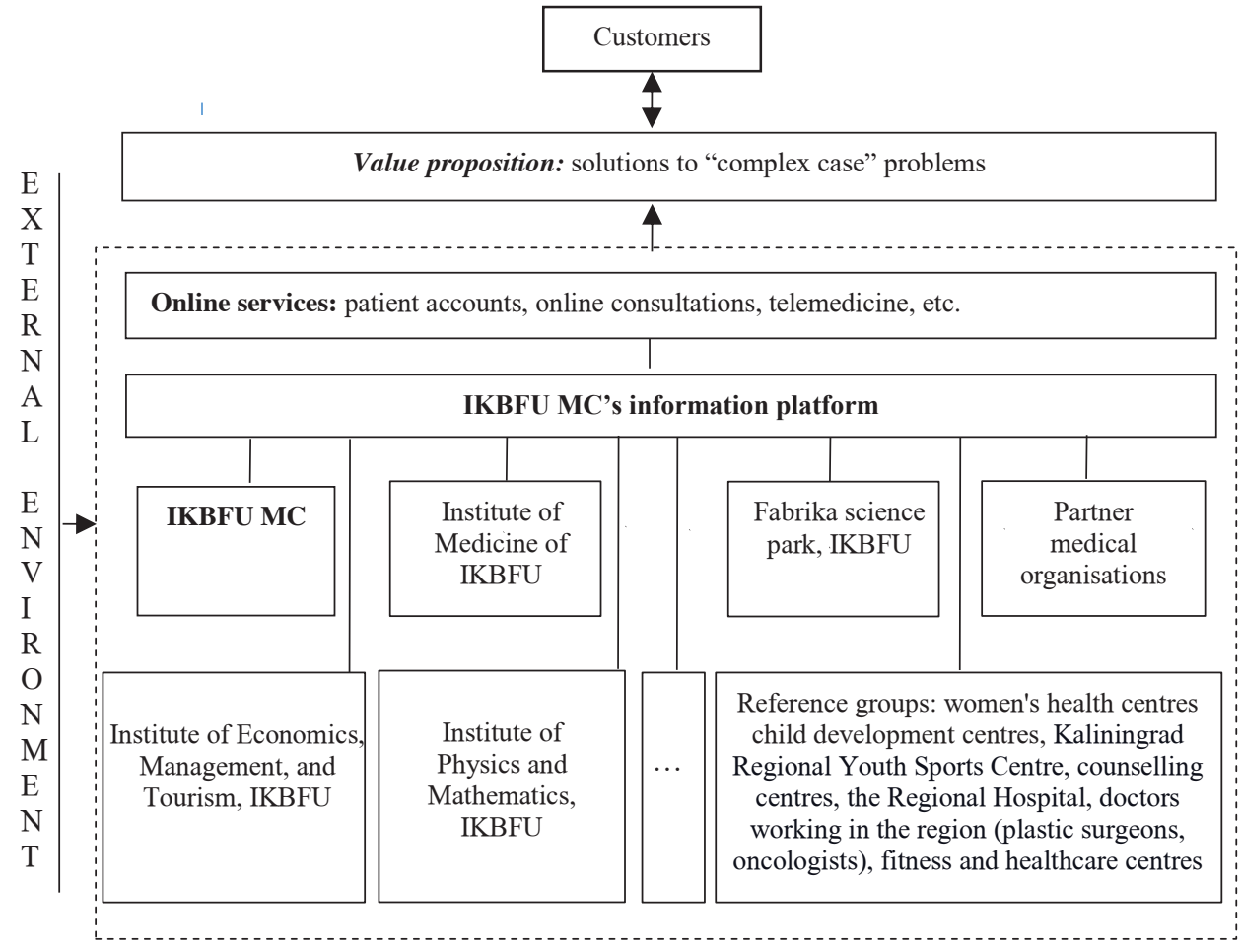

Fig. 2. The platform ecosystem of a university medical centre (the case of the IKBFU MC)

The innovation ecosystem of the IKBFU MC should focus on generating a new value proposition, which is the provision of "complex case" medical services. "Complex cases" are conditions that require more than one physician office visit, consultations from highlyqualified speciality doctors, state-of-the-art diagnostic and other medical equipment, and a rehabilitation system. To this end, the ecosystem should meet the following conditions:

- continuous patient management from an initial visit until full recovery;

- $\quad$ patient management by several speciality doctors for comprehensive treatment;

- joint efforts of participants in the medical service ecosystem (doctors, the academic community, partner medical institutions, reference groups, etc.);

- proactive implementation of new services at the IKBFU MC, in line with current trends and customer expectations, to treat the "complicated case";

- $\quad$ high motivation of all participants in the ecosystem etc. the system, etc.

\section{Methods and approaches}

According to Moore's methodological approach to business ecosystems [3, p.77], the ecosystem of the IKBFU MC is at the initial stage of development. He distinguishes four life cycle phases of ecosystems: birth ("work with customers and supplied to define the new value proposition around a seed innovation"); expansion ("bring the new offer to a large market by working with suppliers and partners to scale up supply and to achieve maximum market coverage"); leadership (provide a compelling vision for the future that encourages suppliers 
and customers to work together to continue improving the complete offer"); self-renewal ("work with innovators to bring new ideas to the existing ecosystem").

The faculty and students of the Institute of Economics, Management, and Tourism conducted a study of a platform ecosystem for the IKBFU MC at the request of the university management. The primary goal was to develop a new marketing policy for the centre. The study included the following elements:

- analysing the centre's current marketing communications and developing a promotion system in the regional for-profit medical services market;

- analysing demand for the centre's services in the regional for-profit medical services market;

- $\quad$ analysing the brand of the centre and developing a concept for its image;

- developing a payment scheme for the employees of the centre.

We supervised the field research and performed analytics on the first two elements.

The methodology of the study included:

- a desk study of the regional competitors' communication policies, best practices in Russia, and successful cases of university medical centres;

- benchmarking competitors' communications in the for-profit medical services market;

- $\quad$ field marketing research of potential and existing customers of the IKBFU MC;

- a desk study of demand for IKBFU MC's services in the for-profit medical services market;

- field marketing research of the potential of the IKBFU MC: a survey of IKBFU MC doctors.

The study into an ecosystem for the IKBFU MC aimed to answer the questions of the centre's management and test several hypotheses. To reach this goal, we asked potential clients to:

- $\quad$ assess potential demand for "complex case" medical services, their awareness of such problems among potential customers (residents of the Kaliningrad region), and the degree to which these issues are being resolved;

- describe how they manage "complex cases";

- name additional services they would like to be offered when receiving treatment for a "complex case";

- $\quad$ say whether they were willing to pay extra for prompt and professional medical services.

Our study of the internal environment of the ecosystem, i.e. the medical staff of the centre, sought to:

- clarify the characteristics and criteria of a "complex case" from the perspective of medical specialities;

- identify the degree of doctors' awareness of the IKBFU MC's positioning as a "complex case" medical centre and their willingness to work within this concept; form a list of new basic services (treatment programmes, services packages) in the priority areas of the IKBFU MC, within the concept of a "complex case medical centre";

- $\quad$ study the feasibility of services package in the centre's priority areas;

- $\quad$ provide descriptions of services packages for all the priority areas;

- compile a list of additional services strengthening the positioning of the centre as a "complex case" establishment; 
- confirm the willingness of doctors to provide additional services, including telemedicine and online consultations;

- draw up a list of resources necessary for providing additional services (equipment, advanced training, higher salaries, etc.);

- $\quad$ to create a list of potential partner organisations and reference groups.

\section{Results}

The desk study of demand for services provided by the IKBFU MC analysed statistics on regional incidence and visits to doctors specialising in the centre's priority areas. General and primary morbidity rates increased for all diseases in the Kaliningrad region in 2013-2018, except for mental disorders, and ear and mastoid disease) [8]. The most significant increase was observed in circulatory, urogenital, endocrine, immune, and liver diseases, neoplasms, and metabolic disorders. There was also a rise in the cases of melanoma and other skin tumours - thee most common malignant neoplasms in the region's population. There was also an increase in the incidence of psychosis and dementia in children aged 0-14 years. The overall number of non-psychotic mental disorders was increasing from 2017. Still, the number of children diagnosed with mental retardation was steadily decreasing. One can safely expect an up to 3-5\% annual rise in demand for services in obstetrics, gynaecology, and urology because of an increase in the number of cases and more frequent visits to doctors of these specialities, including gynaecological oncology. Analysis of web searches by keywords relating to the priority services of the IKBFU MC confirmed our conclusions. The most frequent Yandex queries relevant to the priority areas of the IKBFU MC can be subsumed under obstetrics and gynaecology (34\%), neurology and child psychiatry (17\%), and dermatology and cosmetology (16\%). Analysis of demand based on the field marketing survey of potential customers of the IKBFU $\mathrm{MC}$ and their interest in the centre's priority areas shows the following:

- $\quad 85 \%$ of respondents visited commercial medical centres in 2019-2020;

- the socio-demographic profile of respondents corresponds to the structure of the general population of commercial medical centres' potential customers in the Kaliningrad region;

- almost $80 \%$ of respondents used commercial dental services, about a half of respondents paid for diagnostics services (ultrasound imaging), and $44 \%$ for consultations of gynaecologists and urologists;

- the priority areas of the IKBFU MC's product policy sees steady average demand from regional residents.

medical or thematic websites

individual approach to each "complex case" customer

package offer: examination and diagnostics telemedicine and recruitment of specialists from beyond the Kaliningrad region

setting up interdisciplinary medical teams on customer request

specialist clinics

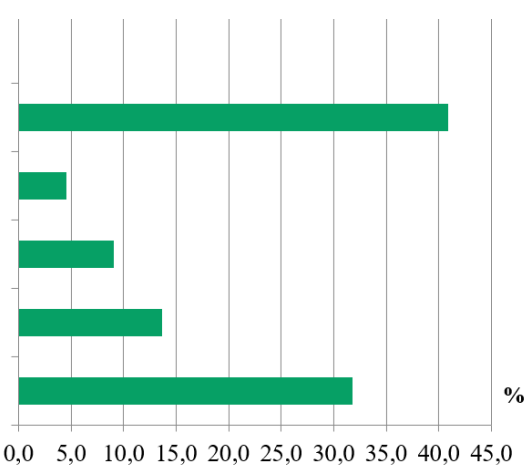

Fig. 3. Approaches to "complex case" problems 
The analysis of regional residents' health issues demonstrated that the most sought-after areas of medical expertise were, firstly, gynaecology, obstetrics, urology, secondly, instrumental diagnostics, and thirdly neurology.

In its turn, the analysis of demand for "complex case" medical services showed that half of the respondents had encountered "complicated cases", whilst $40 \%$ had never solved their health problems. This conclusion rests on answers to the question: "Have you, your children, or your parents had "complex case" health problems (those that cannot be solved by a single physician doctor visit and which require highly-qualified specialists, and state-of-the-art diagnostic and other medical equipment)?"

The analysis of methods employed by potential customers of the IKBFU MC in addressing their "complex case" problems (Fig. 3) revealed the following:

- greater patient confidence in specialist clinics;

- trust in individual approaches to "complex cases";

- the need for a broader range of medical services and additional offers, including telemedicine (doctors from outside the Kaliningrad region can be recruited);

- client-initiated consultations; package offers, including examination, diagnosis, treatment, and rehabilitation.

The study showed that the main criteria used by the target audience when selecting a medical centre were the doctor's popularity and recommendations from familiar and trustworthy specialists. Respondents also paid attention to the speciality of the centre, its pricing policy, and the condition of the equipment. No one mentioned attractive interior and exterior design, comfortable waiting areas, and good customer service as significant factors. We believe that the focus on the quality of medical services confirms that potential customers have "complicated case" problems and face difficulty resolving them.

The analysis of approaches to the "complicated case" problem on the supply side was based on interviews with doctors - leading specialists of the IKd-for BFU MC. Its results suggest the following:

- the concept of "complicated case" is ambiguous and difficult to define;

- the leading specialists of the IKBFU MC should conduct an additional in-depth study into the "complicated case" concept for different specialities;

- $\quad$ the product policy of the IKBFU MC should include "complicated case" services for different specialisations: outpatient surgical care, genetic counselling, individual treatment protocols, prescription of cosmetic products for at-home routine, etc.;

- the product policy of the centre should include service packages and treatment and rehabilitation programmes for various specialities;

- there is a need to involve partners specialising in individual services, treatment and rehabilitation, such as health resorts and healthy lifestyle service providers, in treating "complex cases";

- doctors should be ready to provide additional services contributing to the positioning of the MC as a "complex case" medical facility (telemedicine, online consultations, multidisciplinary medical teams);

- doctors should be prepared for long-term care of patients as part of the treatment programme;

- improving the qualifications and motivation of the staff requires additional resources and initiatives: encouragement to enter a new speciality; purchasing equipment; advanced training; higher salaries.

All interviewees emphasised the need to change the existing approach to patient management, in particular: 
- $\quad$ to introduce the principles of continuity and flexibility in patient management from an initial visit until complete recovery or remission;

- $\quad$ to set up multidisciplinary teams to manage "complicated cases";

- to launch full-cycle service including diagnosis, treatment, rehabilitation, and follow-up.

The first phase of IKBFU MC ecosystem creation is the development of a "complex case" value proposition, which requires a system of unique services and treatment programmes (diagnosis or rehabilitation). The necessary steps at this stage are:

- $\quad$ compiling the list of services (treatment programmes);

- $\quad$ establishing criteria for service uniqueness;

- $\quad$ identifying what services and treatment programmes have been effective;

- measuring the innovativeness and uniqueness of medical equipment and technology used in delivering services;

- describing the doctor's experience, the accuracy of diagnostic tests, and other features of the services;

- $\quad$ emphasising the advantages of receiving treatment at the IKBFU MC.

Another focus of the research was an examination of the centre's current communication policy. We produced practical recommendations on a sequence of communication activities (Internet marketing, POS-materials, content marketing for the "Services" and "Doctors" sections of the IKBFU MC website ), increasing the functionality of the website, and an advertising campaign for the centre, etc.

Institutes of the IKBFU can and should be involved in ecosystem formation. The Institute of Medicine will become the intellectual centre for the development of the "complex case" concept and speciality treatment programmes (diagnostics and rehabilitation). The Institute of Economics, Management and Tourism will create a financial and economic framework for the IKBFU MC ecosystem. It will also promote the centre in the region, Russia, and neighbouring countries as a provider of for-profit medical services.

It is also vital to establish contacts and develop collaborations with stakeholders, i.e. reference groups. The research has shown that the reference groups can include women's health clinics, child development centres, Kaliningrad Regional Youth Sports Centre, counselling centres, the Regional Hospital, students and employees of the IKBFU, doctors working in the region (plastic surgeons, oncologists), etc. Reference groups such as educational institutions (schools, universities, secondary vocational training institutions), the sports and fitness industry (fitness, wellness, and nutrition centres), waste management companies, and relevant authorities have a central role in encouraging a responsible attitude to one's health and the environment.

An efficient regional ecosystem for medical services, particularly one including the IKBFU's innovative ecosystem, will be possible if ecological well-being is achieved in the region.

\section{Conclusions}

1. Creating an innovation ecosystem for a commercial university medical centre will contribute to sustainable regional development based on a green growth model. It will help regional healthcare achieve high international standards.

2. The formation of such an ecosystem at the IKBFU MC, as well as relevant research, is in its initial phase - which is the development of a value proposition. Our study has shown that, despite the competitiveness of the Kaliningrad market of for-profit medical services, demand for "complex case" medical care has not yet been met. This market segment requires a special approach to positioning the medical centre and a unique value proposition 
embracing innovative diagnostic and treatment methods and a range of additional medical services. All this will ensure individual and continuous management of a patient from diagnosis to complete recovery and rehabilitation. This problem can be solved systemically through establishing and developing an ecosystem for for-profit medical services at the IKBFU MC. As the earliest phase of ecosystem formation, the new value proposition ("complex case" medical services) warrants internal transformations at the centre to bring a new vision for for-profit medical services based in an individual approach, comprehensive and continuous patient management, additional "complex case" speciality services, a wide range of online services ensuring flexibility and continuity of care, etc.

3. The study has framed a promotion and communication policy for the IKBFU MC as a "complex case" medical facility. A produce policy has been developed along with a forecast of demand for the centre's unique product. The findings presented in this article were obtained within the project "Developing a marketing policy for the IKBFU Medical Centre".

4. The proposed approach to for-profit medical services is in line with current trends in the development of national and regional economic systems underpinned by the principles of sustainable development, an effective demographic policy, and green growth. Its primary benefits are the preservation and replacement of local human resources, a new attitude to one's health, the environment, and natural resources, and the development of ecological needs in society.

\section{Acknowledgement}

The authors are grateful to students of management of the Institute of Economics, Management, and Tourism for their help in field marketing research.

\section{References}

1. SDG Indicators: Global indicator framework for the Sustainable Development Goals and targets of the 2030 Agenda for Sustainable Development. Official website of the United Nations. A/RES/71/313, 21 (2018-2020) https://unstats.un.org

2. G. B. Kleyner, Enterprise ecosystem in the light of systemic economic theory, 88 (Moscow: TsEMI RAN, 2018)

3. J. F. Moore, Predators and prey - A new ecology of competition. Harvard Business Review, 71(3), 75 (1993)

4. J. F. Moore, The death of competition: Leadership and strategy in the age of business ecosystems (New York: Harper Collins, 1997)

5. M. G. Jacobides, C. Cennamo, A. Gawer, Strategic Management Journal, 39(8), 2255 (2018)

6. G. B. Kleyner, M. A. Rybachuk, V. A. Karpinskaya, Manager, 11(4), 2 (2020)

7. R. Ron Adner, Journal of Management, 43(1), 39 (2017)

8. Health care in the Kaliningrad region in figures (2017-2018, 2015-2016 and 2013-2014) (statistical and reference yearbooks), https://www.infomed39.ru 